\title{
Demographic Change and Labour Markets
}

by

\author{
Katerina Lisenkova \\ University of Strathclyde \\ Ronald W. McQuaid (*) \\ Edinburgh Napier University
}

Robert E. Wright

University of Strathclyde

October 2009

Revised January 2010

(*) Author to whom all correspondence should be addressed: Employment Research Institute, Edinburgh Napier University, Craiglockhart Campus, Edinburgh, EH14

1DJ, UK, r.mcquaid@napier.ac.uk 
Running title:

"Demographic Change and Labour Markets"

\begin{abstract}
Two processes are expected to increasingly characterise demographic change in the $21^{\text {st }}$ century in many countries - population ageing and potential population decline. Although there are links between population ageing and population decline, they will affect the labour market in different ways. As a population ages, so will its labour force, with an increasing share of older workers and a decreasing share of younger workers. Assuming no changes in age-specific labour force participation rates, population decline will result in a shrinking of the labour force, particularly those where the female participation rates are already high. Developed and developing countries are going to be affected by these demographic processes in different ways during the next four or so decades. Both groups of countries are going to experience labour force ageing. However, the size of the potential labour force in developing countries will still increase significantly during this period, while it is likely to decline in many developed countries. To address the issue of increasing dependency associated with a declining labour force, developed countries are likely to try to increase productivity and labour force participation rates, especially of older workers, as well as to use immigration to counteract labour force decline.
\end{abstract}

Keywords: ageing, productivity, labour markets 


\section{Demographic Change and Labour Markets}

\section{Introduction}

When considering the impact of demographic change on the labour market in the $21^{\text {st }}$ century, it is useful as a first step to focus on two specific changes: population ageing and potential population decline. Population ageing is the rise in the average or median age of a population - it is an increase in the relative share of people in the older age groups (e.g. aged 65 and above) and a decrease in the relative share of people in the younger age groups (e.g. aged 15 and below). Population decline, in this paper, is simply a reduction in the number of people in a in a country. Although there are links between population ageing and population decline (e.g. both are driven primarily by long-term fertility decline, although the former is also driven by increased longevity), they are different and will affect the labour market in different ways.

As a population ages, so will its labour force, with an increasing share of older workers and a decreasing share of younger workers. As labour force participation rates (the percentage of a given age group that is in the labour force - i.e. working or looking for work) decline as people get older, especially after about 50 years old, more aged population will therefore have fewer people in the labour force for a given population size. Also actual population decline will generate a fall in the labour force if participation rates remain unchanged. In this sense, population decline/labour force decline and population ageing/labour force ageing go hand-in-hand.

It is important to stress that population ageing is not just a "rich country problem". The populations of "developing" countries are also ageing (see Bloom, Canning and Fink in this issue). Most of these countries are some time away from when their populations are expected to decline. However, challenges and problems 
associated with population ageing/decline in developed countries provide some insights into "things to come" in these countries. Despite this, we know of few studies that have explored the implications of population ageing on the labour markets in developing countries (a recent exception is Vodopivec and Arunatilake, 2008).

The remainder of this paper is organised as follows. Section 2 begins with background information on the extent of population and labour force ageing and decline in developed and developing countries. Section 3 discusses problems associated with population and labour force ageing and decline. Section 4 concentrates on potential policy responses that would lessen the negative consequences of both. A brief conclusion follows in section 5 .

\section{Background}

The total population of the world and of "developing" and "developed" countries for the period 1950-2050 is shown in Figure 1. These future population estimates are taken from the United Nations population projections (United Nations, 2008). This paper uses their classification of countries with those of North America and Europe along with Russia, Japan, Australia and New Zealand being classified as "developed". All other countries of the world are classified as "developing”. It is clear that any such division and labelling of countries will be contentious. However, we adhere to United Nations view that the designations "developed" and developing" are intended for statistical convenience only, and do not necessarily express a judgement about the stage reached by a particular country or area in the economic development process. Most importantly, this division allows us to empirically illustrate and highlight key cross-national demographic differences.

$<<<<$ Figure 1 about here $>>>>$ 
Figure 1 shows that the population gap between developing and developed countries has grown larger since 1950. More specifically, in 1950 the world population was estimated to be around 2.5 billion, with about two-thirds of this total consisting of people living in developing countries. Currently, the world population is estimated to be about 6.7 billion, with around 80 per cent living in developing countries. If the United Nations population projections prove to be accurate, by 2050 over 85 per cent of the world population of 9.1 billion will be concentrated in developing countries.

To further illustrate what is likely to be a large difference in the future rates of population growth between these two groups of countries consider Figure 2. This figure emphasises this difference by setting the population size of the two groups to 100 in the year 2010 in order to eliminate differences in scale. The projections suggest that by 2050 the population of developing countries will grow by about 40 per cent while the population of developed countries will grow by, at most, 3 per cent. In addition, in the developed countries group, there are many countries whose populations are projected by the United Nations to decline in this period (for example most countries in Eastern Europe, see Lisiankova and Wright, 2005).

$<<<<$ Figure 2 about here $>>>>$

Figure 3 shows the population of those between the ages of 15 and 64 . This age group is of special interest from a labour market point of view, since in most countries the vast majority of people in employment fall in this age range. In developed countries employment is even more concentrated, mostly in the 20-64 age group since a larger share of the 15-19 age group is in education. For example, in Scotland, data from the 2001 Census indicates that of the total number of people 
employed (both part-time and full-time), about 95 per cent are aged between 20 and 64. On average, in developing countries the rates of employment amongst young adults and (unfortunately) children are higher than in developed countries. Because of this, we will follow the convention used in most cross-national comparative research by considering the 15-64 age group as the so-called "potential labour force", noting that this is likely to be a less than ideal measure.

$$
<<<<\text { Figure } 3 \text { about here }>>>>
$$

It is not surprising that the general pattern shown in Figure 3 is similar to Figure 1. In 1950, there were about 1.5 billion people in this age group, with twothirds of this total living in developing countries. Currently there are about 4.4 billion, with over 80 per cent in developing countries. The United Nations projections suggest that this number will grow to 5.9 billion by 2050 , with nearly 90 per cent of this total living in developing countries. In other words, over time the potential global labour force has become progressively more concentrated in developing countries (to an even greater extent than the concentration of the population as a whole) and this trend is expected to continue over at least the next four decades. Figure 4 is similar to Figure 2 but focuses on the 15-64 age group. In the period from 2010-2050, for developing countries, the population in this age group is expected to increase by about 39 per cent. This is about the same as for the total population. However, in developed countries the population in the 15-64 age group is expected to decline by about 11 per cent over the same period, even though the overall population is expected to increase by about 3 per cent. If these population projections prove to be accurate then the potential prime age labour force in developed countries will contract considerably in the future, even with some in-migration and slightly higher fertility rates than today.

$<<<<$ Figure 4 about here $>>>>$ 
As mentioned above, the populations of both groups of countries are expected to age in the future. However, this will also influence the ageing of their respective labour forces. One way to measure labour force ageing is to consider changes in the ratio of "older to younger workers". Although there is no agreed definition of what is an older or younger worker, it is usually assumed in applied research to be between the ages of 30 and 40 years. To illustrate the differences in labour force ageing between developing and developed countries, we have selected age 35 as the dividing line.

Figure 5 shows the population aged 35-64 relative to the population aged 1534 expressed per 100. In 1950, in developed countries there were 109 older workers for every 100 younger workers, while in developing countries it was only 77 . It is interesting to note that this measure fell steadily until around 1985 in developing countries while in developed countries it changed only marginally. However, since 1980-85 it has increased in both groups of countries. According to the United Nation projections this measure will continue to increase on an almost linear trend in developing countries until the end of the projection period in 2050 . On the other hand, this measure will increase in developed countries until around 2025-2030 and after that it will fall marginally.

\section{$<<<<$ Figure 5 about here $>>>>$}

What is clear from Figure 5 is that over the next four decades the ratio of older to younger workers will be considerably higher in developed countries, as has been the case in the past. However, the expected rate of future labour force ageing will likely be much higher in developing countries compared to developed countries. Evidence in support of this is given in Figure 6. This figure shows the same information (population aged 35-64 relative to the population aged 15-34 from 2010 
to 2050), rescaled to 100 in 2010 for both groups of countries. The difference is striking. If the projections prove to be correct, this measure will increase by over 50 per cent in developing countries. However, in developed countries, it will change relatively slightly, first increasing and then decreasing. By 2050, it will only be about 8 per cent higher than its value in 2010 .

$<<<<$ Figure 6 about here $>>>>$

\section{The Problem}

Why does the ageing of the labour force matter? There are various mechanisms through which changes in the age structure may affect an individual's "success" in the labour market. For the purpose of illustrating the key points in the discussion below, we will follow the approach pioneered by Freeman (1976) which divides an individual's working life into two stylized "career phases". The first is a "learning phase" and the second a "senior phase", although it is easy to imagine additional phases. In simple terms, individuals in the learning phase tend to be younger with less work experience, while individuals in the senior phase tend to be older with more work experience. Younger workers are complementary to older workers - the former assist the latter thereby gaining experience. As most economic activities use a mixture of inexperienced and experienced workers, the productivity of older workers depends on the productivity of younger workers and vice-versa. The effects of this balance will, of course, vary according to factors such as the rates of technological, structure of employment and demand changes.

If we accept, for purposes of illustration, the simplifying assumption that these are two distinct, non-homogeneous groups of workers then the law of diminishing returns implies that an exogenous increase in the size of one group, relative to the 
other, will reduce that group's productivity relative to the other, ceteris paribus. For example, an increase in the number of younger workers relative to older workers will lower the relative productivity of younger workers and increase that of older workers. In this case, there will be more inexperienced workers to assist experienced workers, but relatively fewer older workers to mentor or assist younger ones. On the other hand, an increase in the number of older worker relative to younger workers will increase the relative productivity of younger workers and decrease that of older workers. In this case, there will be fewer inexperienced workers to assist experienced workers. If wages are a positive function of productivity, all else being equal, in this simple model we would expect changes in the number of older workers relative to younger workers to affect their relative earnings, i.e. an ageing work force would lead to relatively high wages for younger workers. Of course there are many complexities that could be added, and cases where younger workers may be more productive, but this provides a useful broad, stylized perspective.

Although it is straightforward to present a formal model that demonstrates these effects, such a model is not presented here since the problem can be easily understood in terms of simple supply and demand in the labour market. The impact of population ageing can be thought of as an increase in the supply of older workers coupled with a decrease in the supply of younger workers. These supply shifts will generate several effects. First, the number of younger workers employed will decrease, while the number of older workers employed will increase. Second, assuming that the labour market adjusts, the average wage of younger workers will increase while the average wage of older workers will decrease. Third, there is no classical unemployment in this model since in both "segments" of the labour market, labour supply equals labour demand. In other words, the exogenous changes in labour 
supply generated by population ageing are absorbed by the relative wage of youngerto-older workers increase. It is important to note that this new level of employment (i.e. fewer younger workers and older workers) corresponds to the maximum level of output production, given a fixed stock of capital and constant technology. However, this new level of total employment may be higher or lower.

This simple wage adjustment mechanism will only occur in labour markets where wage rates are free to move upwards and downwards. Clearly this is not the case in most countries. Labour unions, minimum wage laws and employment legislation, which may make it difficult (and expensive) to hire and shed workers, introduce a significant degree of wage rigidity into the labour market. In this situation, the response to changes in the number of younger workers relative to older workers will not be entirely through relative earnings - the relative employment and unemployment rates of the two groups of workers will be affected. In this sense, the impact of changes in the age structure of the labour force can be thought of as a "trade-off" between earnings and employment effects, under these simple assumptions. If labour markets do not adjust, then population ageing may generate unemployment, potentially for both older and younger people. For more discussion of the earnings and unemployment effects and their relative significance see: Fertig and Schmidt (2005), Klevmanken (1992), Korenman and Neumark (2002), Schmidt (1996), Shimer (2001), Welsh (1979), Wright (1991), Zimmerman (1991).

Why does the decline in the size of the labour force matter? Simple supply and demand economic models suggest that to a large extent it is the interaction between labour demand (potential employers) and labour supply (potential employees) that determines the level of employment and wages paid. The population projections discussed above suggest that the potential supply of labour will decrease 
substantially in developed countries. This will lead to increased competition in the labour market for workers, which will put upward pressure on wages.

If producers of goods and services are forced to pay higher wages, because of demographically-generated labour shortages, they will become less competitive in both domestic and international markets, which in turn will lead to lower rates of economic growth unless productivity increases (e.g. through better technology and skills development and their improved utilisation). Lower rates of economic growth imply lower tax revenue growth and governments could face greater difficulty in meeting the increased levels and standards of public services demanded by their ageing electorate. This will provide an incentive for governments to change the productivity, type, level and scope of services provided and/or raise taxes. These may in turn interact with in- and out-migration, population change and economic growth.

\section{Policy Implications}

As discussed above, the problems associated with labour force decline and labour force ageing are more acute in developed countries given they are further along their demographic transitions with both mortality and fertility at historically low levels. Therefore this section will focus on some possible policy responses that might be adopted in these countries.

One response is to "do nothing". It is worth remembering that population ageing is a transitory phenomenon. Most industrialised countries have experienced below replacement-level fertility for at least three decades and it seems unlikely that fertility is going to increase dramatically in the near future, although it should be noted that Myrskyla et al. (2009) have shown that those countries scoring highest on 
the World Bank's "human development index" have had recent fertility increases (but are still well below the replacement level).

There are different views on future mortality changes. One is that future improvements in mortality are expected to be relatively modest, with life expectancy only increasing slowly in the coming decades. Another view is that large increases can to be expected, with life expectancy reaching 100 years in some countries (see Bloom, Canning and Fink in this issue; Oeppen and Vaupel, 2002). However, without large and sustained levels of positive net-migration, the age structure of these populations will stabilise in this century. This is the so-called principle of "ergodicity" (see Sharpe and Lokta, 1911), which implies that if fertility and mortality rates stay stable there is a point where the relative population shares in each of the different age groups will become constant.

In this sense, the problem of population ageing is an adjustment problem generated by a "one-off" movement from a "younger" to an "older" age structure caused by a "one-off" demographic transition and exacerbated by a large "one-off increase" in fertility associated with post-war baby booms that occurred in most developed countries. If the population age structure stabilises then so will the age structure of the labour force along with demographic dependency ratios. However, because fertility in most developed countries has been below replacement level for some time, their populations and labour forces are likely to decline (or continue to decline) in the future.

Hence, some argue that the best approach is simply to "ride out the storm", since this situation of changing age structure (and its resulting socioeconomic challenges and problems) is a temporary phenomenon. It is often argued that once the age structure of a population stabilises, low rates of economic growth will be needed 
to generate standard of living improvements. This is thought to be true especially if there will be higher levels of inter-generational wealth transfers (e.g. fewer children sharing inheritances). Such an approach may be costly in standard of living terms in the adjustment period, at least for some groups (e.g. those with little inheritance or with many siblings to share the inheritance with). Therefore, it is likely to be politically difficult and it is unsurprisingly that this is not currently advocated by any Government that we are aware of, although some groups have welcomed population reductions for environmental reasons. So what else can be done?

\section{Labour Force Participation}

A declining population or even a new stable population structure may require changes in work patterns and labour market participation, for instance older retirement ages and less early retirement, so as to mitigate otherwise higher dependency ratios. This suggests that policies that increase the potential supply of labour are desirable. Figure 7 shows the labour force participation rate for individuals aged 15 and older since 1980 (ILO, 2008). Several points about this graph are worth noting. The first is that throughout this period, the overall participation rate for developed countries has been lower than for developing countries. The second is that this rate has declined slightly for both, although there were sharper changes in some countries during the middle of the twentieth century (see McQuaid, 2007). However, this average decline disguises changes among different age groups.

$$
<<<<\text { Figure } 7 \text { About Here }>>>>
$$

Figure 8 shows the labour force participation rates for "older people", defined as people aged 55 and older. Rates are shown for three specific age groups: 55-59, 6064 and $65+$. In both developed and developing countries, participation declines with 
age. For the 55-59 age group, these estimates suggest that the participation rate is about the same in both developed and developing countries-around 60 per cent. With respect to the other two groups, the participation rate is considerably higher in developing countries. More specifically for the 60-64 age group, the participation rate is currently around 40 per cent in developed countries and around 50 per cent in developing countries. For the $65+$ age group, the gap is even more marked, with the rate about 10 per cent in developed countries and nearly 30 per cent in developing countries, although this followed a drop in the decades before 1980. The participation rate has increased slightly for developed countries for those under 65 , especially during the 2000 s, partly due to a relatively buoyant economy in the mid-2000s and reduced early retirement (which in the past has been relatively common for older workers during recessions).

\section{$<<<<$ Figure 8 About Here $>>>>$}

Figure 9 shows the labour force participation rates for "younger people", those aged between 15 and 29 years, in three specific age groups: 15-19, 20-24 and 25-29. At this end of the age distribution, participation increases with age. The participation rate for the 15-19 age group has declined in this period in both groups of countries, primarily reflecting increased participation in secondary and tertiary education, with the current labour market participation rate being around 35 per cent in developing countries and around 30 per cent in developed countries. The rate for the 20-24 age group has also declined, probably for reasons of greater tertiary education participation, and is currently around 65 per cent in both developing and developed countries. According to International Labor Organization (ILO) estimates, there has been little change in this period in the participation rate for the $25-29$ age group, 
although this data source suggests that the rate is higher in developed countries (83 per cent) compared to developing countries (78 per cent).

$<<<<$ Figure 9 About Here $>>>>$

The estimates presented in Figures 7 to 9 suggest that the labour force participation rates of older workers are relatively low. With increasing life expectancy in developed countries, many argue that the age of retirement, usually around age 60 to 65 , is too low. "Age of retirement" is usually interpreted as the age at which one is entitled to a state pension, or a private pension in those occupations where retirement is mandatory. By increasing the age of retirement, some people will be "forced" to work to an older age, while others may welcome the opportunity to work longer for a variety of reasons.

One popular view is that increasing the age of retirement would increase the potential supply of labour by increasing the potential supply of older workers. However, the labour force participation estimates presented in this section suggest that simply increasing in the age of retirement might not have the full expected effect on the size of the potential labour force. People in developed countries often choose to stop their career long before the official retirement age. Labour force participation in pre-retirement age group of 60-64 is only about 40 per cent (see Figure 8), although there was a modest increase in recent years from low of 32 per cent in 1999 to 41 per cent in 2007 .

One important factor influencing a voluntary early retirement decision is considered to be an implicit tax on continued work. This is the negative financial return on continued work and continued pension contributions compared with early retirement and early drawing on retirement benefits. As demonstrated by Duval (2003), by age 60 this implicit tax reaches 30 percent on average in OECD countries. 
A large number of people retire before they qualify for state pensions through social transfer programmes such as invalidity, unemployment and early retirement schemes, or through early retirement pensions, often after redundancy, perhaps supplemented by part-time or other work. These programmes create additional incentives for early retirement.

To increase labour force participation of older workers governments could introduce incentives and remove disincentives relating to continued employment and early retirement. However, broader changes in the labour market, education systems and health services are required in order to provide employment opportunities for older workers and to maintain their employability (Dixon, 2003). Whether this supply increase would be translated into employment would also depend on labour demand, the types and conditions of jobs and the wages that were on offer from employers. These wages, on average, might be lower (and perhaps considerably lower) that what was on offer before the age of retirement was raised.

A further group of policies relate to increasing the labour force participation of women. The figures presented in this section mask what are large differences in the labour force participation rates between men and women, especially women with children (who have had a tendency to move to part-time employment or withdraw from the labour market). Although female labour force participation has increased markedly during the past 50 years, particularly in developed countries, there are still large cross-country differences. Factors such as social attitudes, availability of flexible working arrangement, child friendly policies (e.g. parental leave, childcare and eldercare provision) and the absence of distortional taxation of second earners, affects female labour force participation. Policies that make it easier for women to combine child rearing and long-term employment and careers will likely have positive effect 
on female labour force participation. For example, Jaumotte (2004) in an OECD study quantified the key factors influencing female labour force participation, suggesting that if best practice policies were introduced in all OECD countries, female labour force participation would increase by about 10 percentage points on average.

\section{Labour Productivity}

If the size of the labour force declines, and there is no change in participation rates, then the so-called "economic dependency ratio" will increase. This ratio is simply the ratio of people "in-work" relative to those "not-in-work". It is usually proxied by the number of people aged 15-64 relative to the number of people aged 014 and aged 65+. In 'pay-as-you-go' welfare states, which are the norm in many developed countries, those currently "in-work" pay for those currently "not-in-work". If demographic trends continue, and participation rates remain unchanged, it is likely that the number "in-work" will decline while the number "not-in-work" will increase. If the standard of living is not to fall, then those in work will have to pay for an increasing number of those "not-in-work", which emphasise the need for long-term labour productivity increases (or greater immigration), ceteris paribus.

Figure 10 shows a crude measure of labour productivity. This measure is gross domestic product in constant 2005 US dollars, adjusted for purchasing power parity, expressed per person aged 15 to 64 (World Bank, 2009). Measured in this way, in developed countries labour productivity increased from about $\$ 30,000$ in 1980 to over $\$ 50,000$ in 2007. Although this change seems impressive, it only represents an average annual growth rate of 1.75 per cent. The current level of labour productivity for developing countries as a group is approaching $\$ 2,500$.

$<<<<$ Figure 10 About Here $>>>>$ 
Figure 11 shows the same measure of labour productivity for a selected group of developed countries and for the so-called BRIC countries: Brazil, Russia, India and China. The highest level of productivity is in the United States (c. £65,000) followed by Germany (c. £51,000) the United Kingdom (c. £51,000) and Japan (c. £48,000). Labour productivity is much lower in Brazil (c. £14,000) and Russia (c. £20,000) while India (c. $£ 4,300)$ and China (c. $£ 7,700)$ currently lag even further behind.

$$
<<<<\text { Figure } 11 \text { About Here }>>>>
$$

In a very detailed study of the impact of labour force decline and ageing on labour market performance in Germany, Borsch-Supan (2003) separates two potential impacts of these demographic processes on aggregate productivity. The first is the effect of changing age composition arising from different age-specific labour productivity. The second is higher capital intensity resulting from declining labour supply. According to his calculations the former will have negative albeit not very large impact on aggregate productivity, while the latter will have larger positive impact. Thus, the overall impact would be positive. However, he also shows that this productivity increase would not be enough to compensate for the declining labour force size. The solution that he suggests is that the productivity of the labour force has to be increased through human capital formation as well as increased capital utilisation and technological improvements.

This might be done partly through a range of policies such as: better basic and advanced education, lifelong learning and improved skills development and crucially the better utilisation of skills that people have. Labour productivity can be increased by educational reforms that result in schooling and training systems that produce graduates that complement capital-intensive and skill-intensive domestic production. It has been argued that recent increases in labour productivity, at least partially, can be 
explained by growing participation rates. In the context of population ageing the system of (life-long) education and skills development will have to be significantly reformed. Higher education and other institutions will have to transform themselves in the light of the declining number of young people, who traditionally represented majority of those involved in education. More attention should be devoted to training and skills development among older workers, as they have a lower propensity to undertake this (OECD, 2005). Such policies increase their labour force participation and productivity. It should again be noted that older and younger people are not necessarily perfect substitutes in employment or education.

\section{Immigration}

It is possible to estimate the size of net-migration that a country requires in order to sustain economic growth and standards of living. For example Lisiankova et al. (2006), use a computable general equilibrium (CGE) model of the Scottish economy, to investigate the impact of labour force decline on macro-economic performance. One finding was that Scotland (with a population of 5 million) needs a net-migration of at least $+20,000$ per year in order to avoid negative output growth.

Many European Union countries experienced large inflows of immigrants from the countries that joined the EU in 2004. These countries are mainly from Central and Eastern Europe, with Poland having the largest population size. However, many analysts have argued this wave of immigration has been short-lived and these countries cannot provide large numbers of immigrant workers in the long-run (see for example, Lisiankova and Wright, 2005; Hollywood et al., 2007). In this sense, the EU (and other developed countries) will have to look further afield for potential migrants 
if they wish to try to maintain their labour forces and populations through immigration.

Managed migration from growing developing countries can be a potential source of immigrants and it can be argued that a suitable immigration policy could be effectively used to increase the supply of workers in developed countries. Potentially central to this approach are immigration systems that "match people to jobs" such as the Canadian "points system" or the German "guest worker" programme (or some combination of the two). Of course, as many authors have argued, international migration can be a very controversial and sensitive issue and has to be effectively managed (Martin, 2004). Wealth and relative economic development rates and the degree of outsourcing of work from developed countries are also important factors.

\section{Concluding Comments}

Population ageing across the globe, and especially in developed countries, is a major challenge facing workers, pensioners, employers, and governments. In this paper global demographic trends leading to labour force ageing and labour force decline have been discussed. It has been shown that although both developed and developing countries are going to experience labour force ageing over the next four decades there are large demographic differences between these two broad groups.

One such difference is the projected change in the potential labour force. While the population aged 15-64 is expected to increase significantly in developing countries it is expected to decline in developed countries. This may lead to relatively higher growth rates among many developing countries. A key to accommodating labour force ageing and labour force decline is to increase both labour force participation and productivity, amongst both older and younger people. 
Such objectives could be obtained through a combination of policies targeting later retirement, greater flexibility in pension provision, moves towards higher activity rates for older workers including those past state pension ages. Another complementary policy option is to increase immigration from high labour supply developing regions to low labour supply developed countries, unless the latter choose policies to manage population decline. However, even policies to "do nothing" will have profound effects on the future population and labour force changes.

\section{References}


Bloom, D. E. Bloom, Canning, D. and G. Fink (2010) The graying of global population and its macroeconomic consequences, Journal of the Academy of Social Sciences, this issue

Borsch-Supan, A. (2003) Labour market effects of population ageing, Labour, 17, 544

Dixon, S. 2003 Implications of population ageing for the labour market, Labour Market Trends (February), 67-76

Duval, R. (2003) The retirement effects of old-age pension systems and other social Transfer Programmes in OECD Countries, OECD Economics Department Working Paper No. 370, OECD, Paris

Fertig, M. and C. Schmidt (2005) Gerontocracy in Motion? European cross-country evidence on the labor market consequences of population ageing, in Scotland's Demographic Challenge (Ed.) R.E. Wright, Scottish Economic Policy Network, Stirling

Freeman, R. B. (1976) The effects of demographic factors on age-earnings profiles, Journal of Human Resources, 14, 289-318

Jaumotte, F. (2004) Female labour force participation: Past trends and main determinants in OECD Countries, OECD Economics Department Working Paper No. 376, OECD, Paris

Hollywood, E., Brown, R., Danson, M. and R.W. McQuaid (2007) Demographic and labour market change: The dynamics of older workers in the Scottish labour market, Scottish Geographical Journal, 123, 242-256

International Labour Organization (2008), Estimates and projections of the economically active population: 1980-2020, ILO, Organization, Geneva

Klevmarken, A. (1993) Demographics and the dynamics of earnings, Journal of Population Economics, 6, 105-122

Korenman, S, and D., Neumark (2002) Cohort crowding and youth labor markets: A cross-national analysis, in, Youth Employment and Joblessness in Advanced Countries (Eds.) D. Blanchflower and R. Freeman, NBER Comparative Labor Market Series, University of Chicago Press, Chicago 
Lisiankova, K., P. McGregor, N. Pappas, K. Swales, K. Turner, and R.E. Wright (2006) Macroeconomic impacts of demographic change in Scotland, Economics and Social Research Council Swindon

Lisiankova, K. and R.E. Wright (2005) Demographic change and the European Union labour market, National Institute Economic Review, 194, 74-81

Martin, P. (2004) Population and migration: Challenge paper, Copenhagen Consensus Centre, Copenhagen

McQuaid, R.W. (2007) The Aging of the labor force and globalization, in Globalization and Regional Economic Modelling (Eds.), R.J. Cooper, K.P. Donaghy and G.J.D. Hewings, Springer-Verlag, Heidelberg, pp. 69-85.

Myrskyla, M., H.-P. Kohler, and F.C. Billari (2009) Advances in development reverse fertility declines", Nature, 460, 741-3.

Organization for Economic Co-operation Development (2005), Education and training policy promoting adult learning, OECD, Paris

Oeppen, J. and J.W. Vaupel (2002) Broken limits to life expectancy, Science, 296, $1029-1031$

Schmidt, C. (1996), “Cohort sizes and unemployment: Lessons for Poland, in Labour Markets by Design? Labour Market Policies and Creative Use of Household Surveys in Transition Economics (Eds.) L. Hartmut and J. Wadsworth, Weltforum-Verlag, Munich

Sharpe, F.R. and A.J. Lotka (1911) “A problem in age distribution”, Philosophical Magazine, 21, 435-438

Shimer, R. (2001) The impact of young workers on the aggregate labor market, Quarterly Journal of Economics, 116, 969-1007

United Nations (2008) World population prospects: The 2008 revision population database, Department of Economics and Social Affairs, Population Division, New York

Vodopivec, M. and N. Arunatilake (2008) The impact of population aging on the labor market: The case of Sri Lanka, IZA DP No. 3456, Bonn

Welch, F. (1979) Effects of cohort size on earnings: The baby boom babies financial bust”, Journal of Political Economy, 87 (supplement), S65-S97

Wright, R.E., (1991), "Cohort Size and Earnings in Great Britain”, Journal of Population Economics, vol. 4, pp. 295-306

World Bank (2009) World development indicators, World Bank, Washington 
Zimmermann, K. (1991) Ageing and the labor market, Journal of Population Economics, 4, 77-200 


\section{Acknowledgement}

We are grateful to two referees for their constructive comments. 


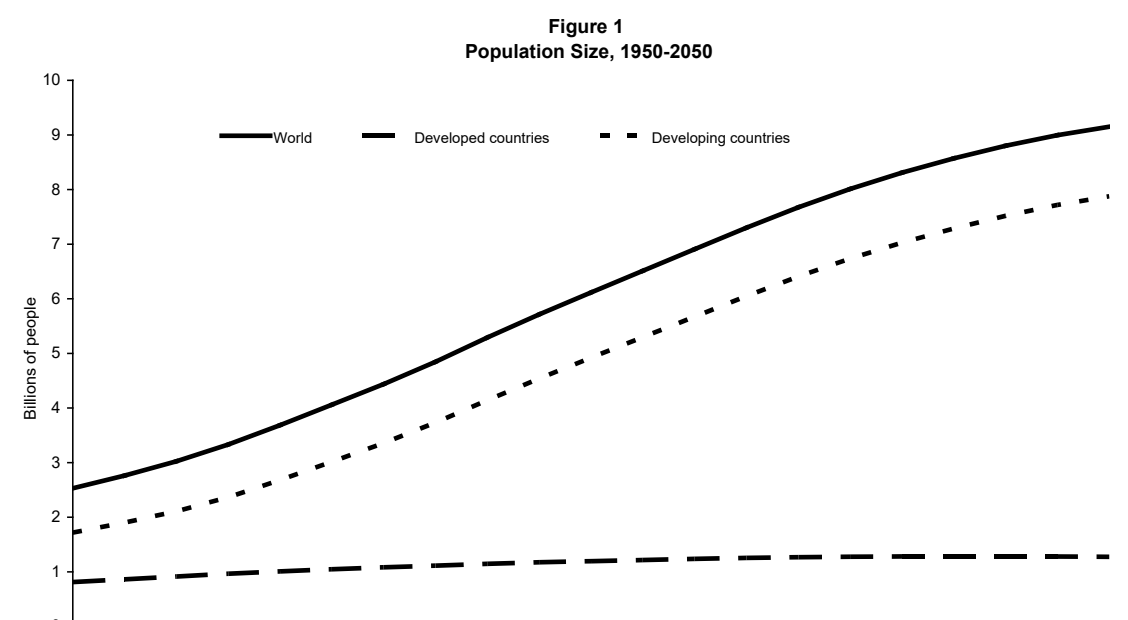

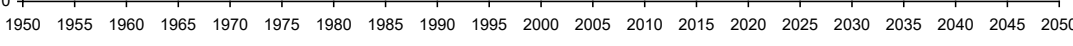

Source: United Nations (2008) 


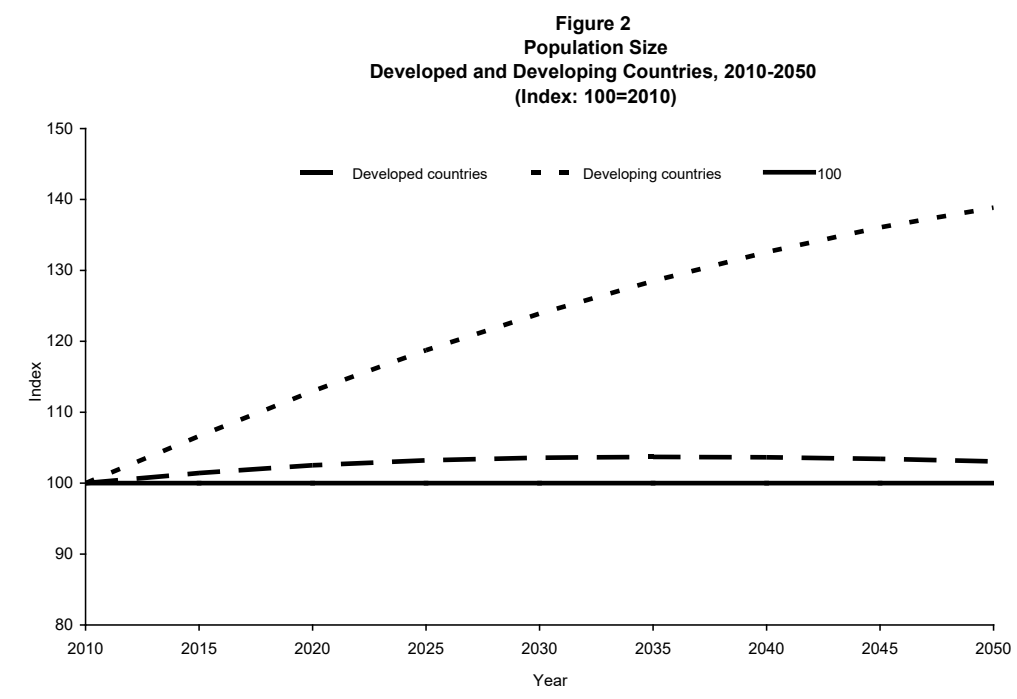

Source: United Nations (2008) 
Figure 3
Population Aged 15-64, 1950-2050

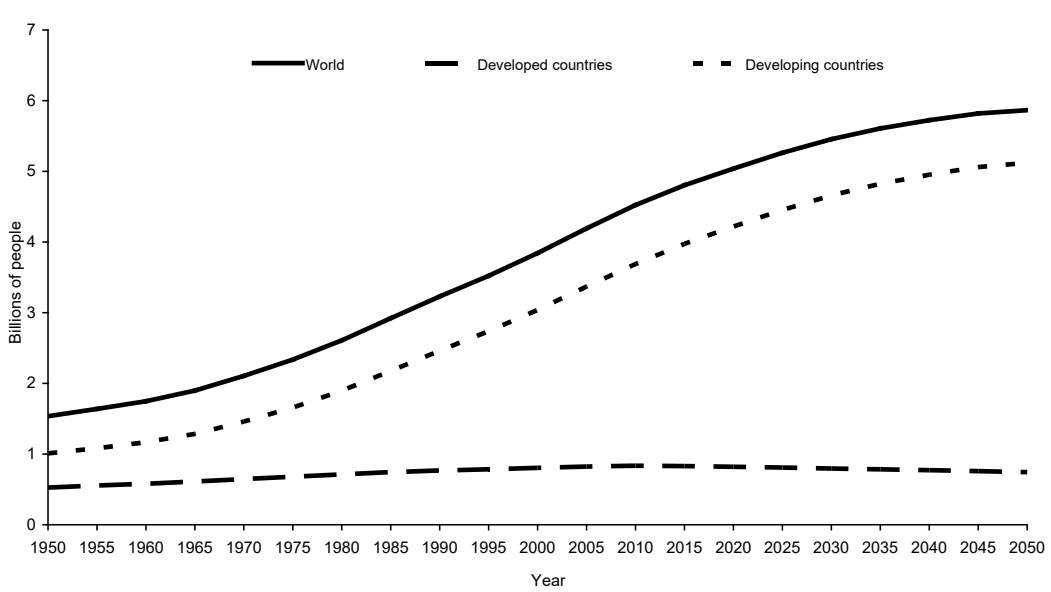

Source: United Nations (2008) 


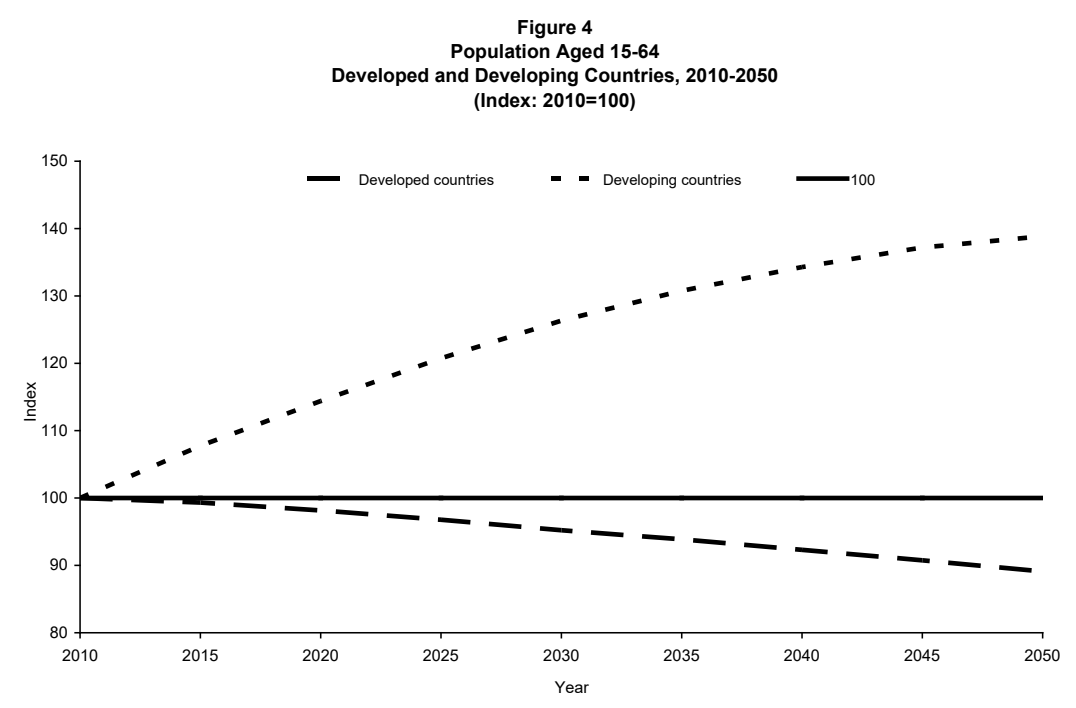

Source: United Nations (2008) 


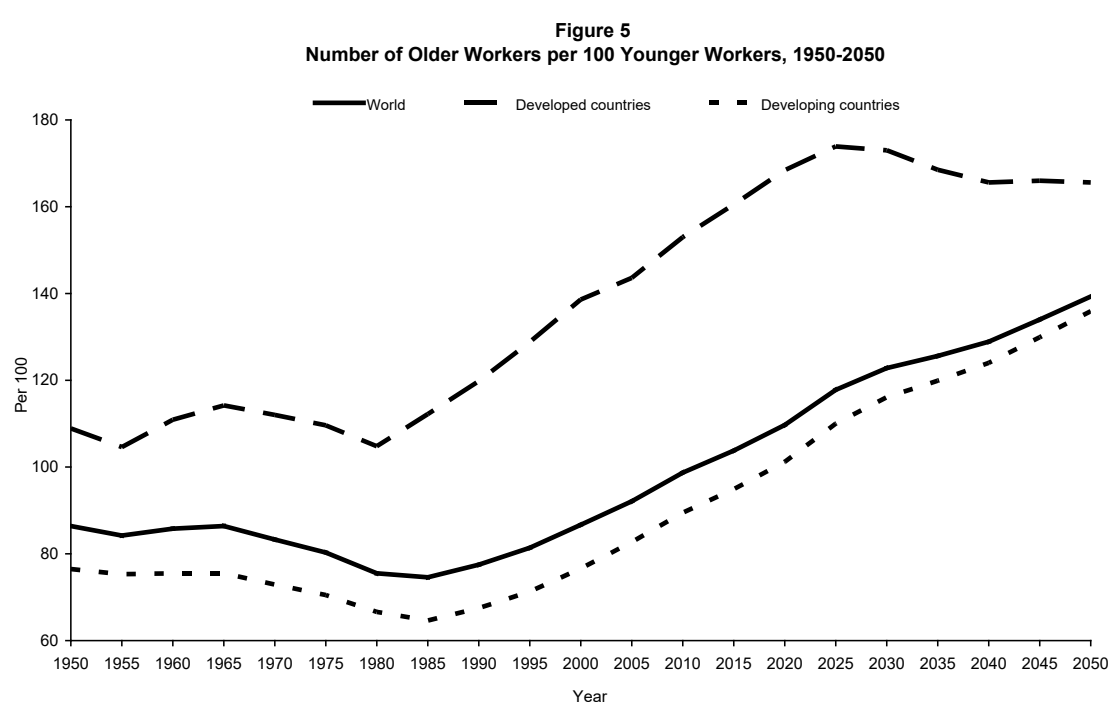

Source: United Nations (2008)

30 


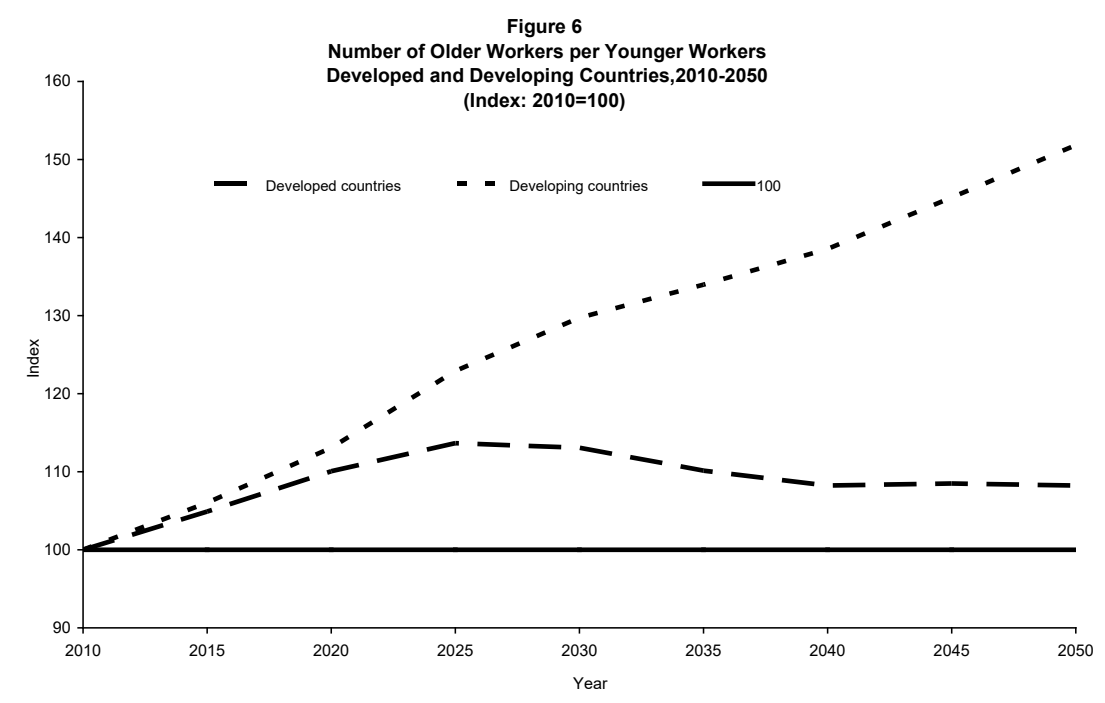

Source: United Nations (2008) 


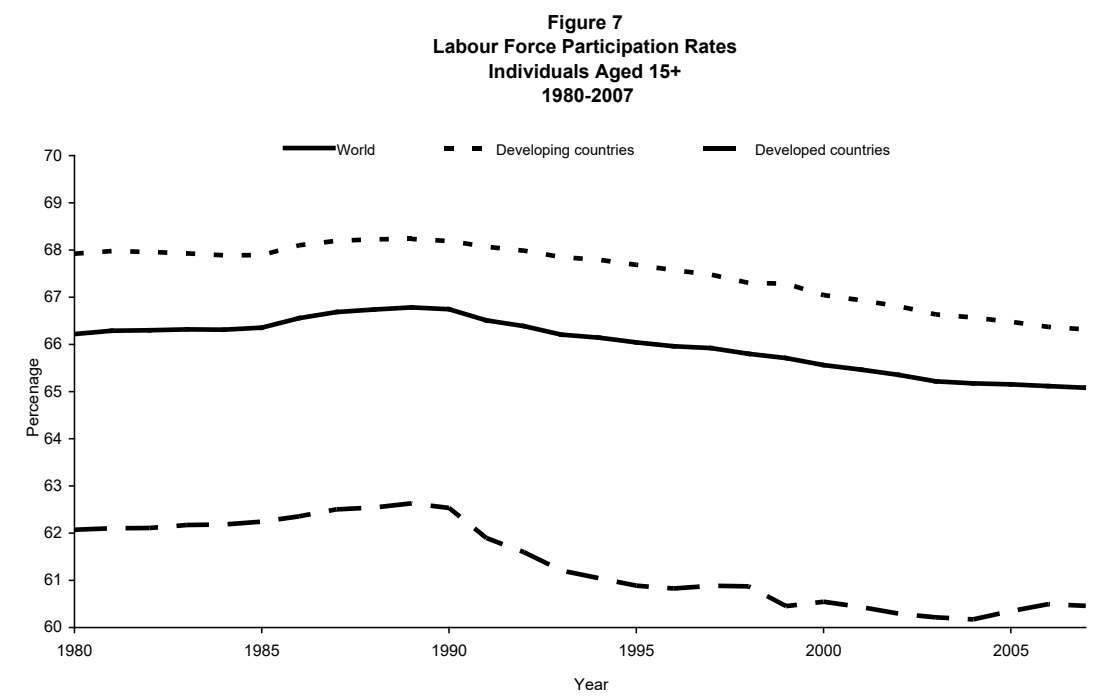

Source: ILO (2008) 


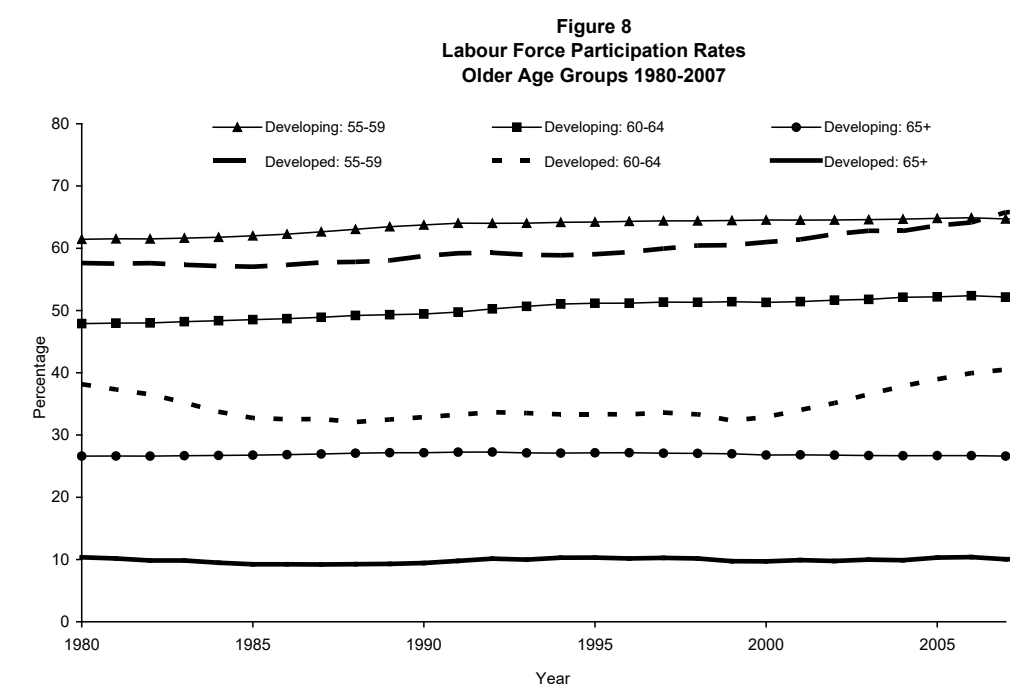

Source: ILO (2008) 


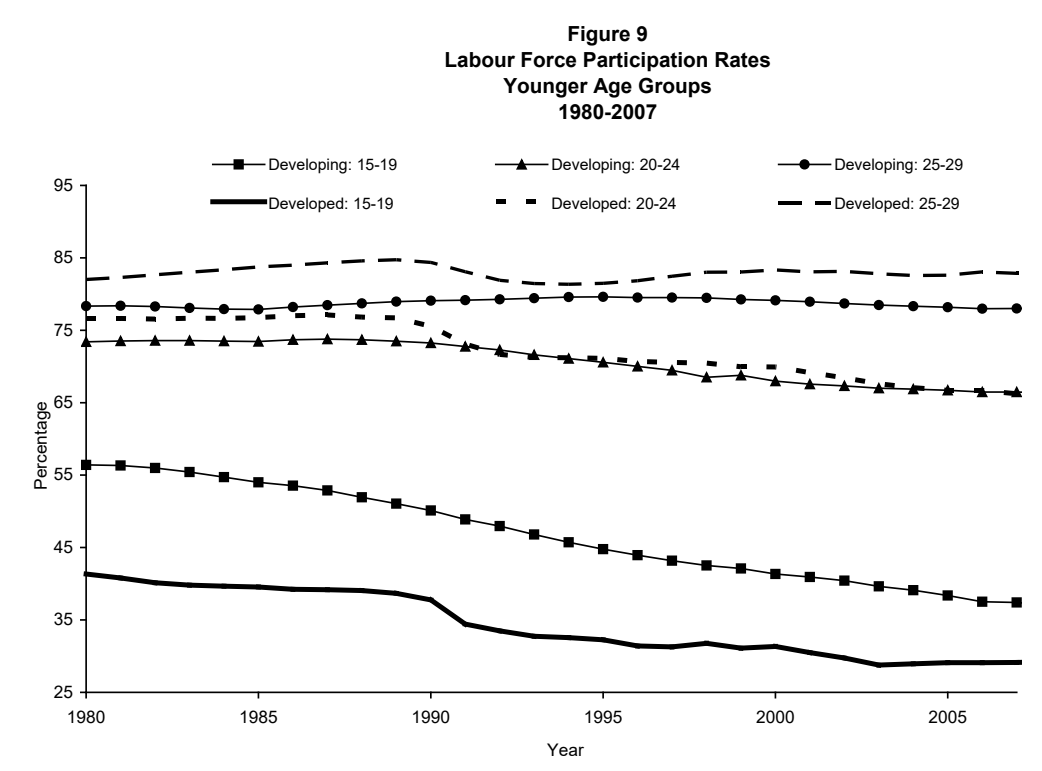

Source: ILO (2008) 
Labour Productivity, 1980-2007

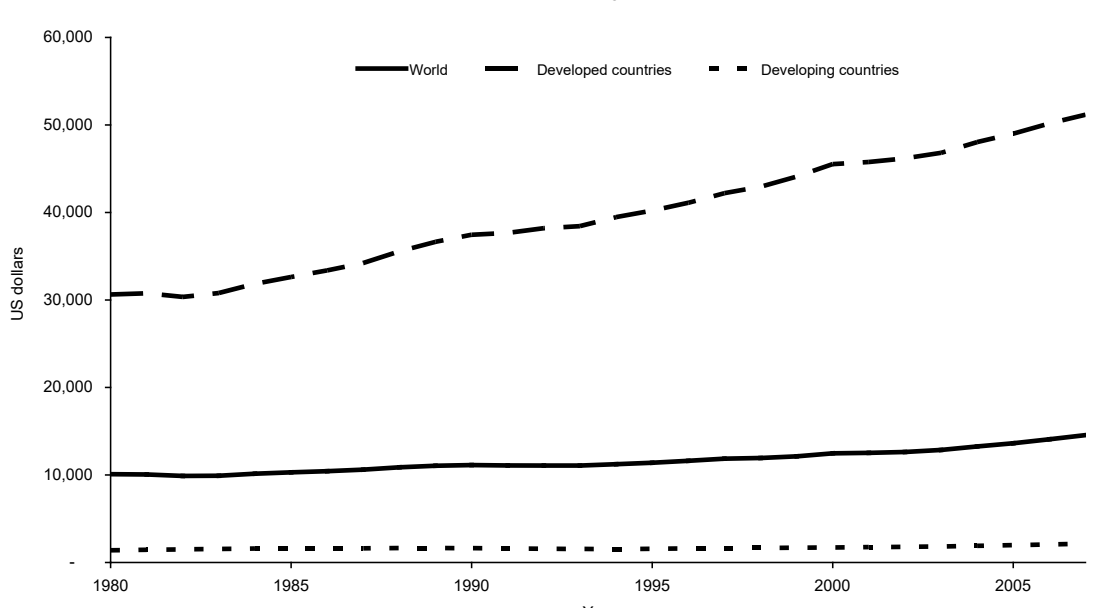

Source: World Bank (2009) 


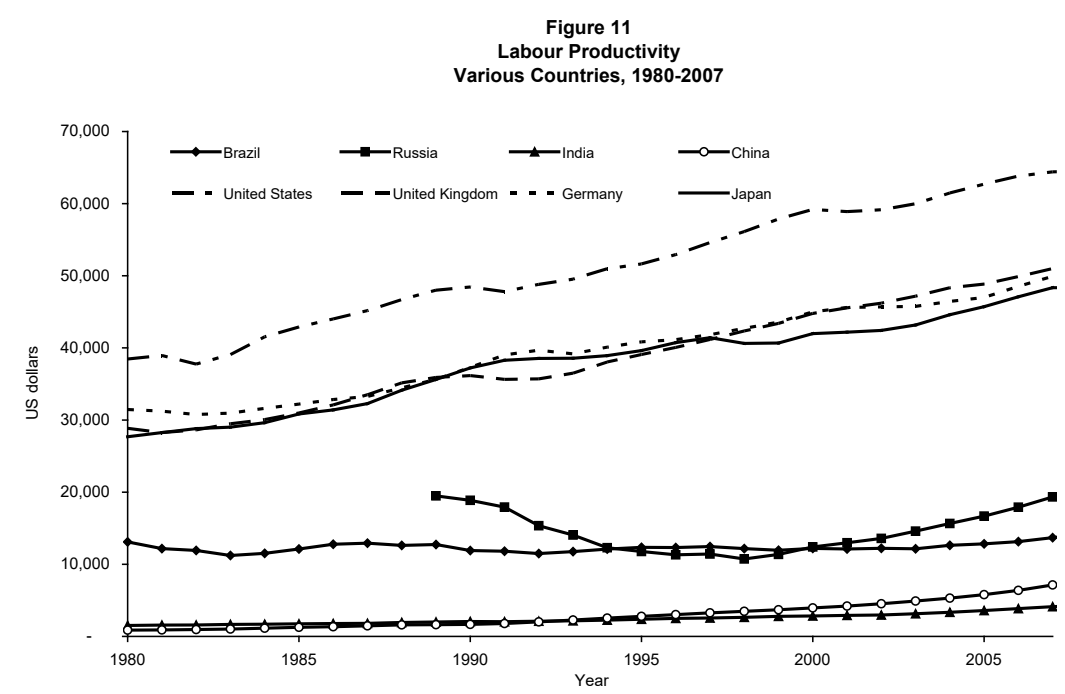

Source: World Bank (2009) 